\title{
Así somos los alter comunicadores que vivimos en zonas de conflicto
}

Z $\mathrm{n}$ este capítulo se presentan una serie de reflexiones escritas y naCrradas por los gestores de la alter comunicación participantes en este estudio. Estas reflexiones permiten re-conocer los tonos y los ritmos narrativos propios de quienes agencian los procesos alter comunicativos en los territorios azotados por la guerra.

Este colofón acerca a los lectores a la voz viva de los alter comunicadores, a sus experiencias, a sus formas propias de contar, y representa un esfuerzo interesante por dar a conocer maneras diversas de vivir la guerra contando la paz. 


\section{Ingakuna estéreo: "Ver, sentir, pero no decir..."}

Waira Nina Jacanamijoy Mutumbajoy - Ingakuna estéreo

En el tema de los conflictos, a veces la parte física queda detrás. Por ello es muy importante crear espacios que estimulen a los estudiantes, por medio de personas que nos pueden ayudar para aprender a comunicar de manera correcta las palabras que queremos expresar desde nuestras culturas, nuestra forma de pensar, como miembros de comunidades indígenas. Para nosotros como equipo pedagógico y de comunicaciones es muy importante poder dar a nuestras poblaciones una voz de aliento, ya que siempre decimos que hace falta contar con el otro, por aquello de que cuando la palabra es sola, se va al vacío.

Por eso hemos venido proponiendo desde Ingakuna estéreo, en el municipio de San José del Fragua, en Yurayaco, comunidad ubicada en el departamento del Caquetá, un mensaje que enseña que mientras el diálogo exista, mientras esté claro a dónde queremos ir, es posible una agenda que nos ayude a abrir los caminos de eso que está escondido, de eso que está invisible, de esos procesos tan bonitos que tienen cada uno de los niños, los ancianos, la comunidad en general.

La propuesta de Ingakuna estéreo inició en el año 2000, en esa época empezamos a reconocer distintas miradas, distintas situaciones que existen en nuestra localidad, y por esto fuimos incluyendo a diferentes entes comunitarios como son: el grupo de las mamas, el grupo de los taitas, el de los líderes, a líderes políticos, a nuestros líderes comunitarios, también a los campesinos, todo para entender cómo podíamos enfrentar la realidad de nuestras poblaciones.

De ahí fuimos armando, poco a poco, una propuesta de agenda, que tal vez no fue tan clara o tal vez nos faltó llenarla de contenido, para poderle dar una apertura mucho más profunda al análisis y a la búsqueda

1 A partir de entrevista realizada a Waira Jacanamijoy, de la emisora comunitaria indígena Ingakuna estéreo. Edición de texto realizado por July Marcela Buitrago, Comunicadora social-periodista. 
de soluciones frente a las distintas situaciones de nuestra emisora, como el hecho de saber cómo decir lo que queríamos llegar a comunicar.

En nuestra comunidad hasta la misma iglesia hace parte de este equipo, y los niños del colegio de Yachaicury que conformaron un colectivo bastante importante. Se empezó haciendo pequeños programas con los niños, los líderes, las mujeres, todos enfocados en el tema de cómo cuidar la parte de la salud, empezando desde la medicina tradicional, y tratando el tema del proceso de fortalecimiento organizativo.

Fuimos aprendiendo a hacer otro estilo de comunicación. Por el simple hecho de estar en medio del conflicto y las balas cruzadas entre dos bandos, las comunidades sencillamente se vuelven de derecha o de izquierda, y todo ello nos obligó a pensar: ¿esto es un conflicto realmente? Fue como un momento donde campesinos e indígenas no sabían para qué grupo coger y en qué leguaje poder hablar.

Esto nos llevó a armar un mensaje muy diferente del tema y de cómo desde la emisora podemos enseñar el proceso de conservación de las aguas y otros temas básicos, pero había restricciones: por ejemplo, nos teníamos que quedar callados en la parte de denuncias de derechos, nosotros teníamos que ver, sentir, pero no podíamos expresar nada. Ver, sentir, pero no decir. Porque tuvimos varias dificultades con la guerrilla y con el mismo Ejército.

A usted lo obligaban a hacer cosas que benefician a estos grupos, así de simple, y hubo un momento en el que la guerrilla quería que la emisora comunitaria indígena pasara los CD y los comunicados de ellos sobre la revolución de izquierda. Tuvimos que decir: "No, esta no es una emisora de la guerrilla, esta es una emisora indígena". Después llegó el Ejército y también quisieron usarnos, porque a ellos no les entraba señal de teléfono, de Internet, y como nosotros conectábamos algunos cables y nos cogía señal muy bien, pese a que no había otra clase de conexión, entonces la emisora se convertía en el medio de Internet, en celular, en el teléfono para ellos, en todo eso se convertía la emisora.

Entonces asumimos una forma de denuncia. Empezamos a hacer todo un proceso de radio, radio-teatro, radio-novelas. Empezamos a armar otras formas, otros personajes, diciendo unas realidades concretas 
de la zona de maneras distintas. Esa fue como una de las experiencias más grandes que tuvimos en esta época. Pero no podíamos seguir y decíamos: "no se puede decir esto porque hay que estar calladito". Siempre es muy complicado ese tema de decir.

Yo pienso que la emisora nace con el motivo de transformar esas diferentes realidades dentro de nuestras poblaciones indígenas, para fortalecer la parte de nuestra cultura, nuestras prácticas tradicionales. Entonces, reforzamos mucho toda la parte cultural, y así fuimos como bien, hasta ahora que por medio de toda la trama de voces que vienen con diferentes discursos, no era posible tener un programa que nos llevara a denunciar las diferentes situaciones que se estaban presentando en la zona por causa del conflicto. Nosotros como emisora, desde el 2000 , hemos estado en todo el conflicto, lo que nos ha tocado es puro conflicto, hasta el punto de que la torre de transmisión de la emisora fue tumbada dos veces, tiroteada varias veces.

Por todo eso nosotros tomamos la decisión de callarnos, muchos líderes nos callamos, porque juntas partes estaban vigilando, todo porque nosotros no podíamos hablar en un leguaje de denunciar a ninguno, y en esa situación nos tuvimos que callar.

La emisora llega con ese motivo de no centrarse en ninguno de los bandos, sino de transmitir otras formas de supervivencia y resistencia desde la parte de la medicina tradicional, de la conservación, desde la educación, desde la formación misma, desde la parte del arte. Eso fue muy importante para la emisora, sin embargo nos han dejado callados. 


\title{
Piamonte estéreo: "Lo que tenemos lo hemos conseguido con las uñas..."2
}

\author{
Carlos Martínez Cuellar - Piamonte estéreo
}

Por estar nosotros en la parte sur del departamento del Cauca, tenemos grandes dificultades para lograr un enlace con las emisoras comunitarias que están al norte del mismo departamento. He intentado tener alguna cercanía y procurar unos programas que nos ilustren, que nos conduzcan a tener más claridad en lo que es la búsqueda de la paz, porque tenemos muy claro que el solo hecho de vivir en tranquilidad, no solo en nuestro hogar sino en nuestra comunidad, es parte del principio de una paz que tanto anhelamos en Colombia.

Como emisora comunitaria tenemos dificultades de redes y de acceso a la información. A veces sí podemos "enlazarnos” vía Internet y a veces no, porque la señal es muy mala por esta región. Nosotros intentamos sintonizar programas, y lo hemos hecho con Tele Pacífico, por ejemplo, con todos los programas buenos que tratan de ilustrar a la comunidad, pero desafortunadamente la posición de nuestra área es difícil y se nos cae muy fácil la señal.

Sin embargo hemos creado algunos espacios, considerando que vamos a enriquecer mucho lo que hemos logrado. Como proyectos futuros tenemos un magazine, para que en dos horas muchos actores vengan a decirnos qué está pasando y qué se está llevando a cabo. Esa es como la propuesta que nosotros tenemos desde Piamonte estéreo, pues somos muy jóvenes, escasamente tenemos 18 años [a 2014] como municipio y vamos a cumplir 3 o 4 años de radio. $Y$ en esos años hemos funcionado con grandes dificultades, de todo tipo: lo que tiene que ver con el conflicto (que de eso no hablamos mucho, ustedes sabrán por qué), pero también dificultades operativas que tienen que ver con la misma naturaleza que nos ha golpeado muchísimo,

2 A partir de entrevista realizada a Carlos Martínez Cuellar, de la emisora comunitaria Piamonte estéreo. Edición de texto realizado por July Marcela Buitrago, Comunicadora social - periodista. 
ya que los equipos que hemos conseguido "con las uñas", nos los ha derrumbado o nos los ha quemado la fuerza de la naturaleza... Pero afortunadamente hoy estamos saliendo a buen estado de frecuencia.

Nosotros, los piamonenses, inicialmente identificados como la Baja Bota Caucana, nos consideramos un poco sabios en el proceso comunitario, ya que en el año 96, cuando se inician las fumigaciones contra los cultivos ilícitos, se iniciaron unas marchas para parar las fumigaciones. Le pedíamos al gobierno la no fumigación y por acá los actores armados [la guerrilla de las Farc-ep ${ }^{3}$ ] obligaban a todo el mundo para que hiciera parte de estas marchas. Nosotros como representantes de la comunidad de la Baja Bota Caucana (ya que en ese entonces que no éramos municipio), optamos por hacerle una exigencia al gobierno en la cual decíamos que nosotros merecíamos ser municipio, no tanto porque no fumigaran, porque entendíamos que era una política del Estado, sino para que llegaran más recursos que permitieran a la gente sustentar sus gastos y así no tuvieran que recurrir a los cultivos ilícitos para poder sobrevivir. Por esos motivos considerábamos que nosotros debíamos buscar la municipalidad para esa región.

Así ayudamos a impulsar las marchas [que el país conoció como "marchas cocaleras"] $]^{4}$ para poder presentarnos a nivel departamental y

3 La antropóloga María Clemencia Ramírez, en su libro Entre el Estado y la guerrilla. Identidad y ciudadanía en el movimiento de campesinos cocaleros del Putumayo, señala sobre la relación entre las Farc-ep y las comunidades de su área de influencia, para este caso en la Baja Bota Caucana, lo siguiente: “Según un jefe de acción comunal en Piamonte: 'Las Farc son las que los han capacitado y han hecho avanzar la organización. La guerrilla promueve la asociación de juntas de acción comunal y que la gente se organice; ella pone orden en la región y se acata. Ya la comunidad es consciente de la necesidad de organizarse y da información cuando se hacen censos. Antes no querían colaborar y me trataban de chismoso' (testimonio del jefe de la junta de acción comunal de la Consolata, en Piamonte, 1998).” (Ramírez, 2001, p.157)

4 Sobre las marchas cocaleras, María Clemencia Ramírez cuenta que: "El comienzo de la operación conquista en el Guaviare determinó la hora cero para el inicio de las marchas cocaleras, el 16 de julio de 1996, pocos días después de este discurso presidencial. Los campesinos se movilizaron en contra de la declaratoria de zona especial de orden público, de los consecuentes abusos del Ejército y de las fumigaciones que se realizaron de manera intensa en 
lograr que se sintiera en los dirigentes departamentales para buscar nuestro objetivo: si era posible que pudiéramos ser municipio o no, naturalmente contando con que la región piamonenense es una región petrolera y, por ende, ya estaban las compañías asentadas explotando petróleo. También nos valíamos del bombeo [de la extracción de petróleo] para que estas compañías viniesen a traer precisamente a quienes necesitábamos para lograr el municipio. Palabras más, palabras menos, nosotros logramos en el 96, el 30 de noviembre, que el gobierno nos entregara una ordenanza donde nos dicen que somos municipio.

Allí también nació la búsqueda de una emisora comunitaria. Pero nos enteramos que el gobierno entregaba, cada 10 años, una licencia para que funcionen las emisoras comunitarias. Nosotros creímos que eso era como ir solicitar un crédito y que ya nos iban a facilitar las cosas reuniendo cierta documentación. Pues no fue así, porque nosotros no sabíamos todos los trámites que hay que hacer, y así pasaron unos 10 años. Posteriormente sí obtuvimos, en el 2010, la resolución del Ministerio de Comunicaciones, de las TIC, y fue ahí cuando nosotros comenzamos a hacer opinión.

Por ser este un municipio petrolero, un municipio minero y un poco cocalero, había presencia tanto de los actores armados ilegales,

ese departamento. Los líderes campesinos de los departamentos con cultivos ilícitos, quienes se encontraron en Bogotá durante la realización de un seminario internacional sobre cultivos ilícitos a mediados de 1995, acordaron allí realizar manifestaciones conjuntas cuando se iniciaran las fumigaciones en cualquiera de los tres departamentos. En consecuencia, para apoyar al Guaviare, el 25 y 26 de julio se iniciaron las marchas en el Putumayo hacia los cascos urbanos de Orito, San Miguel (La Dorada), Valle del Guamués (La Hormiga) y Puerto Asís. Casi de inmediato, el 29 de julio, comenzaron en el departamento del Caquetá, donde la Policía Antinarcóticos empezó a fumigar, el 22 de julio, en Remolinos del Caguán (La Nación, 27 de julio de 1996, p.II). El comandante de la Policía en el Caquetá 'anunció que las operaciones en la zona de Remolino del Caguán en esta primera etapa se extenderán a lo largo de 20 días, dependiendo del buen tiempo para las operaciones aéreas, a la vez que no se descartó la posibilidad de fumigar otros sectores del departamento' (La Nación, 24 de julio de 1996, p.II). Ante la inminencia de que las fumigaciones continuaran, los campesinos de esta y otras regiones no tuvieron alternativa distinta a iniciar la marcha hacia Florencia." (Ramírez, 2001, p.137). 
en este caso la guerrilla, y del mismo Ejército, pero desafortunadamente el Ejército sí estaba haciendo presencia en nuestra región, pero en donde estaban directamente las compañías de petróleo. Eso es algo que nosotros hemos criticado fuertemente, porque se ocupaban más de cuidar los tubos que de cuidar la misma población que buscaba un cambio de vida frente a los cultivos ilícitos.

Entonces la presencia de la emisora se convirtió en algo difícil, porque pasan cosas como las siguientes: a mí me llega un día un mensaje un poco fuerte y muy extenso, un mensaje por correo electrónico, donde se me pregunta que: "Hasta donde es posible, señor director, de que nosotros, las fuerzas revolucionarias Farc-ep podamos contar con un espacio de lunes a sábado en la emisora, donde podamos alimentarlo con música de la causa". Yo lo que hice fue llevar el mensaje a la junta programadora, y allá nos sentamos y planteamos nuestra posición. Lo que dijimos fue que nosotros como radio comunitaria estábamos en la necesidad de enrutar, de formar, de educar en todo lo que concernía a nuestra identidad y al rescate de nuestra identidad como colonos y como civiles, así que nos toca decirles que no.

También nos ha pasado con el Ejército. El Ejército y la Policía tienen su emisora, y nosotros aquí en la zona de la Bota Caucana, aquí en Piamonte, no entendíamos porque ellos tenían que autorizar a nuestro medio para circular los contenidos, cuando nosotros hemos dicho que somos netamente comunitarios, y todo a sabiendas de que nosotros tenemos unos seguidores, unas audiencias que son las etnias, los colonos, la población civil, la comunidad. Esos intentos de intervención de los actores armados y las negativas que se hicieron sembraron una preocupación grande en mi familia, y se comenzó a sentir que posiblemente a mí me iban a matar. Mis hijos no querían que yo volviera a ir a la radio, pero yo siempre sostuve que ya había caminado un poco de años con este proyecto y que gracias a Dios he permanecido intacto. Últimamente no me han vuelto a decir nada y es así, de esa manera, como hemos nacido y nos hemos mantenido. 


\section{Ocaina estéreo: selva y encanto en el Bajo Putumayo}

Líverman Rengifo Gómez - Ocaina estéreo

La región de Putumayo, llena de grandeza, es reconocida por personas que han logrado ver con otros ojos esta realidad, realidad que muchos no conocen o no quisieran ver porque están segados por el modelo extractivista al que solamente le interesa lo económico, y no el bienestar familiar, social y comunitario (plan de vida).

En este sentido existe una necesidad urgente de comunicar, de construir, de incluirse en los procesos sociales, porque la comunidad lo requiere. La sociedad, en su mayoría, se siente conformista con lo que se tiene o se hace, pero existe una realidad y es la del miedo o el temor de informar todo lo que se refiera a los grupos armados, legales e ilegales.

Las condiciones no están dadas para hacer este trabajo, pero los medios comunitarios han tomado una posición como gremio que tiene que ver con incluirse en foros y debates, para que se realice una estrategia de comunicación con el fin de socializar y conocer el proceso de paz en terreno.

Es así como desde Ocaina estéreo y la Red Cantoyaco se ha iniciado un franja informativa donde se tratan los temas de movilidad y el proceso de paz, todo referente a cómo van avanzando los diálogos, pero realizando la opinión vox populi a las comunidades y líderes que se han venido empoderando del proceso en la región.

De otra parte, se viene realizando un cuestionamiento a la ciudadanía, para poder construir desde ya un escenario que permita encontrarse y reflexionar sobre un proceso de paz que no termina con la firma de los tratados, sino que inicia un proceso mucho más a largo plazo, por lo que las comunidades y organizaciones sociales debemos tomar una postura en la construcción del proceso de paz desde lo local.

En la reflexión quedan algunos interrogantes como estos: ¿con qué mecanismos organizativos cuenta la región para implementar los acuerdos que se vienen dialogando en La Habana, Cuba, en cuanto al 
desarrollo rural, los cultivos de uso ilícito, la participación política y ciudadana, los derechos a las víctimas, etc.?

Partiendo del proceso de paz a nivel local, como medios de comunicación comunitarios hemos concluido que se debe realizar el reconocimiento a las organizaciones sociales, que desde su quehacer vienen aportándole y apostándole al proceso de paz, desde muchos años atrás. En este sentido, se debe hacer un consolidado de las organizaciones que vienen haciendo este trabajo y que quieren sumarse al proceso. De igual manera, se debe establecer la organización de un comité central que dinamice e impulse el proceso de paz a nivel de región.

Tenemos la urgencia de creer en nosotros mismos, ese paso es fundamental, solo así podremos construir un escenario diferente donde la igualdad, la equidad, el compromiso y el empoderamiento serán componentes presentes en cada mirada, sencilla pero llena de esperanza. 


\section{Alter comunicación: impulso para la paz en las regiones (Resultados)}

- La dinámica informativa de los medios masivos y comerciales de comunicación incide negativamente sobre la posibilidad de los ciudadanos, de acceder a una información amplia y plural relacionada con el conflicto armado, en perspectiva local y regional. Esto lleva a que se establezca una suerte de censura informativa a medida que el discurso mediático se construye, de manera casi que exclusiva, desde uno y solo uno de los puntos de vista intervinientes en el proceso.

- El estado del arte sobre la relación analítica comunicación / paz-conflicto permite ubicar cinco enfoques de discusión: el primero propone a los medios de comunicación como actores "neutrales y objetivos" en el tratamiento de informaciones relacionadas con el conflicto armado. El segundo inscribe a los medios de comunicación en la lógica del conflicto y los señala como actores fundamentales. El tercer enfoque atiende a la necesidad de ver a los medios de comunicación como agentes de paz y promotores de los derechos humanos. El cuarto enfoque considera los impactos del discurso mediático en la opinión pública, y las tensiones que formula el escenario mass mediático a las libertades inherentes a la comunicación, la comunicación política y, en resumen, a la democracia, y el quinto 
enfoque se delimita en el interés de establecer los posibles "estándares de calidad" de la información y de su cumplimiento por parte de los actores de la comunicación mass mediática.

- El conflicto armado incide en las dinámicas de cubrimiento informativo que hacen los medios comunitarios del sur del país, acerca de temas relacionados con el propio conflicto, la guerra y la paz. Al tiempo se establece que las dinámicas de la información también intervienen en las lógicas del conflicto y, sobre todo, en el conocimiento que la opinión pública puede llegar a hacerse, por cuanto los medios instituyen socialmente los referentes simbólicos que posibilitan (o no) entender los contextos y dinámicas en los que se desenvuelve la acción bélica.

- Son múltiples las respuestas de los alter comunicadores a las imposiciones de la guerra sobre el ejercicio comunicativo, respuestas que han reconfigurado los modos como se define la inclusión o exclusión, en las agendas mediáticas locales, de contenidos relacionados con el conflicto y la paz, así como las contribuciones que hacen estos medios en la construcción política de las esferas públicas locales.

- Desde las experiencias vinculadas con el estudio se establecen una serie de aportes a la deliberación de los temas relacionados con el conflicto armado, más allá de las formulaciones teóricas propuestas desde espacios académicos e institucionales. En este sentido, la categoría de "conflicto armado" se reconfigura a partir de los siguientes elementos de análisis ubicados empíricamente: A) El conflicto armado incide (ejerce presión) en las dinámicas comunitarias y comunicativas de los territorios, B) El conflicto armado fragmenta el tejido social, perturba las relaciones comunitarias y promueve el individualismo como estrategia de protección, C) Hay un conflicto social estructural, en el que el conflicto armado es una de sus expresiones, D) Existe una “pedagogía viva del conflicto armado" que dificulta el desarrollo de las “pedagogías vivas de la paz”, E) Prevalece la intimidación de la población civil como estrategia de guerra para vencer al enemigo, F) No existe la "neutralidad civil" en medio del 
conflicto armado, y G) El conflicto armado son los actores armados en el territorio.

- Las tres experiencias de medios comunitarios del sur del país vinculadas al estudio, han construido, cada una desde sus particularidades, representaciones propias sobre la paz y el posconflicto, que permiten destacar los siguientes elementos de análisis: A) La paz es el proceso de paz en La Habana, B) La paz como posibilidad de crecimiento económico y social, C) La paz como incertidumbre, D) Distancias entre la manera como se nombra la paz desde las centralidades, y como se nombra desde la periferia, desde las regiones afectadas por el conflicto armado, E) La discusión sobre el posconflicto ha sido agenciada por la institucionalidad, F) Se considera desde las experiencias que así haya firma de acuerdos entre los actores enfrentados en el conflicto, "aquí todo va a seguir lo mismo...", y G) Con acuerdo o sin acuerdo de paz, las comunidades y sus procesos alter comunicativos tienen que seguir en la lógica de la negociación con los actores de los conflictos.

- Las características, establecidas de manera empírica, que constituyen los procesos de alter comunicación en zonas de conflicto armado son: A) Los alter medios engloban la complejidad del conflicto social y armado, B) Desde la alter comunicación se valoran críticamente los contextos, actores, territorios y estrategias del conflicto armado, C) En los alter medios se aplican criterios editoriales reivindicativos de las comunidades, D) En los alter medios se revelan las "intenciones" informativas de las comunidades, E) Desde la alter comunicación se proponen otras formas y estrategias de producción comunicativa, y F) Desde la alter comunicación se promueve la participación de las comunidades.

- Sobre las incidencias del conflicto armado en la producción de contenidos alter comunicativos, las experiencias señalan la existencia de: A) Censura directa, B) Autocensura, C) Imposición de agendas informativas, D) Desviación de responsabilidades, y E) Estigmatización y criminalización. 
- Sobre las repercusiones comunicativas que el conflicto armado ha generado en las esferas públicas locales, los alter comunicadores de las experiencias plantean que: A) Hay restricción de acceso a argumentos para participar cualificadamente en el debate público del conflicto armado, B) Se instituye, por parte de los actores armados, una versión unilateral del conflicto armado, C) Los medios de comunicación se convierten en escenario de disputa, D) Se presenta una confiscación de la libertad de expresión por parte de todos los grupos armados, y E) Se restringen los espacios de encuentro para el debate público.

- En lo que tiene que ver con las respuestas locales que formulan los alter medios a la "lógica informativa" del conflicto armado, los gestores de la alter comunicación señalan que: A) Los medios son lugares de encuentro para el debate público del conflicto armado, B) Debe darse una descentralización de la figura del periodista responsable de informar, C) Se propone un abordaje "no manifiesto" de la incidencia local del conflicto armado, D) Los alter medios cuestionan la propiedad de los medios masivos de comunicación y gestionan la creación de los propios medios, E) Implementan formatos y desarrollan contenidos alternativos, vinculados con las formas de narrar de las comunidades.

- El conflicto armado tiene incidencia en la construcción mediática de referentes simbólicos (representaciones) sobre el conflicto, la guerra y la paz en territorios del sur de Colombia.

- Si bien es cierto, que los procesos alter comunicativos que desarrollan su trabajo en zonas de conflicto armado no construyen una agenda mediática relacionada directamente con el conflicto armado, sí generan una agenda relacionada con temas y actores que producen conflictos sociales (como la minería y la explotación petrolera), que son fuente del conflicto social y armado contemporáneo en Colombia. De este modo, tratando los temas y problemas propios de sus regiones, los actores de la alter comunicación regional atienden de manera tangencial el contexto de conflicto armado, sin involucrar necesariamente contenidos directos relacionados con los actores armados. 


\section{Referencias}

Abric, J.C. (1994). Prácticas sociales y representaciones. México: Ediciones Coyoacán / CCC IFAL.

Araya, S. (2002). Las representaciones sociales: Ejes teóricos para su discusión. Costa Rica: Facultad Latinoamericana de Ciencias Sociales.

Atehortúa, C. (s.f.). Los derechos fundamentales. Pereira: Universidad Libre.

Ayala, G. y Hurtado, G. (2007). Conflicto, posconflicto y periodismo en Colombia: realidades y aproximaciones. Cali: Universidad Autónoma de Occidente.

Berger, P. y Luckmann, T. (2008). La construcción social de la realidad. Buenos Aires: Amorrortu.

Bock, J. (2013). Las noticias se extinguen en el Bajo Cauca. Bogotá: FLIP. Recuperado de http://flip.org.co/index.php/en/informacion/noticias/ item/552-las-noticias-se-extinguen-en-el-bajo-cauca

Botero, L.H. (2007). Teoría de públicos. Lo público y lo privado en la perspectiva de la comunicación. Medellín: Universidad de Medellín.

Bonilla, J.I. y Tamayo C.A. (2007). Las violencias en los medios, los medios en las violencias. Revisión y análisis crítico de los estudios sobre medios de comunicación y violencia en América Latina 1998-2005. Bogotá: CINEP.

Castells, M. (2010). Comunicación y poder. Madrid: Alianza editorial. 
Centro Nacional de Memoria Histórica (CNMH) (2013a). Informe Basta ya. Colombia, memorias de guerra y dignidad. Bogotá: CNMH-DPS.

Centro Nacional de Memoria Histórica (CNMH) (2013b). Resumen: Informe Basta ya. Colombia, memorias de guerra y dignidad. Bogotá: CNMH - DPS.

Chomsky, N. y Ramonet, I. (1995). Cómo nos venden la moto: información, poder y concentración de medios. Barcelona: Icaria.

Comité Internacional de la Cruz Roja (CICR) (2008). ¿Cuál es la definición de conflicto armado según la definición del DIH? Ginebra: CICR. Recuperado de https://goo.gl/XOzxOy

Contravía (15 de enero, 2011). Seguridad ¿desinformación o realidad? (Documental periodístico, capítulo 239). Bogotá: Morris Producciones.

Correa, M. (junio, 2007). Mecanismos de desinformación que perpetúan los medios de comunicación en el cubrimiento del conflicto armado. Reflexión política, 9(17), 188-196.

Espinel, L. (2012). El discurso, en ensayo sobre la ceguera: una mirada politica y educacional. España: Universidad de la Laguna.

Farc-ep. (7 de agosto, 2013). Diez propuestas mínimas para la democratización de la información y la comunicación y de los medios masivos de comunicación (Comunicado). La Habana, Cuba. Recuperado de http:// goo.gl/PzhzU6

Fundación Para la Libertad de Prensa (FLIP) (2011). ¿La censura en las regiones llegó para quedarse? Informe sobre la situación de la prensa en Colombia 2011. Bogotá: FLIP.

Fundación Para la Libertad de Prensa (FLIP) (2012). De las balas a los expedientes. Informe sobre la situación de la prensa en Colombia 2012. Bogotá: FLIP.

Fundación Para la Libertad de Prensa (FLIP) (2012). Urabá, miedo latente y temas vedados para el periodismo. Bogotá: FLIP. Recuperado de http:/flip.org.co/index.php/es/informacion/noticias/ item/963-uraba-miedo-latente-y-temas-vedados-para-el-periodismo.

Fundación Para la Libertad de Prensa (FLIP) (2013). Protestas: sin garantías para cubrir. Informe sobre la situación de la prensa en Colombia 2013. Bogotá: FLIP.

Galtung, J. (2003). Paz por medios pacíficos. Paz y conflicto, desarrollo y civilización. Bilbao: Gernika Gogoratuz. 
Guha, R. (2002). Las voces de la historia y otros estudios subalternos. Barcelona: Crítica.

Guillén, G. (2008). Noticias de la tierra del olvido. Bogotá: Intermedio Editores.

Hueso, V. (2000). Johan Galtung: la transformación de los conflictos por medios pacíficos. Cuadernos de estrategia, 111, 125-159. Recuperado de http://goo.gl/Civn5L.

Indepaz - Unidad de investigaciones (marzo, 2012). Zonas de consolidación y grupos armados. Revista Punto de Encuentro, 58, 26-36.

Jara, O. (2000). Tres posibilidades de sistematización: comprensión, aprendizaje y teorización. En: Sistematización de experiencias, búsquedas recientes (pp. 7-22). Bogotá: Dimensión educativa.

Jodelet, D. (2003). Pensamiento social e historicidad. Relaciones. Estudios de historia y sociedad, 24(93), 97-113.

Laborie, M. (2011). Actores armados no estatales y modelo de Estado. En: Actores armados no estatales: retos a la seguridad global (pp. 26-64). Madrid: Instituto Español de Estudios Estratégicos. Recuperado de http://www.ieee.es/Galerias/fichero/cuadernos/CE_152_ ActoresArmadosNoEstatales.pdf.

Lechner, N. (2000). Nuevas ciudadanías. Revista de Estudios Sociales, 5. Recuperado de: https://res.uniandes.edu.co/view.php/110/index. php? id=110.

Martín Barbero, J. (2000). Medios, olvidos y desmemorias. Debilitan el pasado y diluyen la necesidad de memoria. Ciberlegenda, 6. Recuperado de http://www.comunicacionyciudadania.org/comunicacion/foro2007/ pdfs/otros/GR_Ciberlegenda_n6.pdf.

Mattelart, A y Dorfman, A. (1972). Para leer al Pato Donald: comunicación de masa y colonialismo. México: Siglo xxi Editores.

Mattelart, A. (1974). La cultura como empresa multinacional. Madrid: Ediciones ERA.

Medios Al Derecho (MAD) (2012a). Los medios en la instalación del proceso de Paz: una actuación contraria a la ética y a la ley. Recuperado de http://goo.gl/Z8DFpX.

Medios Al Derecho (MAD) (2012b). Medios de comunicación y cultura de paz. Notas para la reflexión sobre las responsabilidades de los medios de comunicación frente a posibles acuerdos de paz en Colombia. Recuperado de http://goo.gl/a2BXIN 
Molano, A. (septiembre-diciembre, 1992). Confesión de parte. Revista Análisis político, 17, 100-105.

Moñivas, A. (1994). Epistemología y representaciones sociales. Revista de psicología general y aplicada, 47(4), 409-419.

Morelo, G., Castrillón, G. y Behar, O. (2014). Pistas para narrar la paz. Periodismo en el posconflicto. Bogotá: Consejo de redacción, Plataforma de periodismo, KAS.

Pachón, H (2005). El papel de los medios de comunicación en el conflicto armado colombiano. Memorias desde lo local, 4.

Paredes, C. y Torres C. (10 de julio, 2014). El peligro inminente en el que están los dirigentes de Marcha Patriótica en el Caquetá. Las 2 Orillas. Recuperado de http://goo.gl/tyN2DZ

Pécaut, D. (2001). Crisis y construcción de lo público. En: Encuentro Iberoamericano del Tercer Sector. Lo público: una pregunta desde la sociedad civil, Bogotá.

PNUD (2004). Foro: medios de comunicación y conflicto armado. Bogotá. Recuperado de http://goo.gl/gibcJo

Prensa Rural y Alianza de Medios y Periodistas por la Paz (2013). Los medios masivos replican solamente los argumentos del gobierno. Bogotá. Recuperado de http://goo.gl/g9spTF.

Proyecto CEIS (2011). Primer Foro de Alternativas Comunicativas: "Medios comunitarios, memoria y construcción de lo público”. Bogotá: Proyecto CEIS. Recuperado de http://goo.gl/5xatcC

Raiter, A. et al. (2001). Representaciones sociales. Buenos Aires: Eudeba.

Ramírez, M.C. (2001). Entre el Estado y la guerrilla: identidad y ciudadanía en el movimiento de los campesinos cocaleros del Putumayo. Bogotá: ICANH.

Rateau, P y Monaco, G. (2013). La teoría de las Representaciones Sociales: Orientaciones conceptuales, camplos de aplicaciones y métodos. Revista CES Psicología, 6(1). 22-42.

Rettberg, A. (Coord.) (2002). Preparar el futuro: conflicto y pos-conflicto en Colombia. Bogotá: AlfaOmega, Uniandes, Ideas para la paz.

Rey, G. (2007). Ver desde la ciudadanía. Observatorios y veedurías de medios de comunicación en América Latina. En: La fuga del mundo, escritos sobre periodismo. Random House Mondadori, Bogotá. 
Rincón, O. et al. (2007). Ya no es posible el silencio. Textos, experiencias y procesos de comunicación ciudadana. Bogotá: FESCOL, DeJusticia, C3.

Rincón, O; García, M. y Zuluaga, J. (2008). La Nación de los medios. Bogotá: Universidad de los Andes.

Rodríguez, C. (Editora). (2008). Lo que le vamos quitando a la guerra. Medios ciudadanos en contextos de conflicto armado en Colombia. Bogotá: FESCOL, C3.

Rodríguez, O. (2003). Las Representaciones sociales: Entretejidos de la razón y la cultura. Relaciones. Estudios de historia y sociedad, 24, 81-95.

Rodríguez, T. y García, M. (2007). Representaciones sociales. Teoría e investigación. Guadalajara: CUCSH-UDG.

Ruíz, J. (2003). Representaciones colectivas, mentalidades e historia cultural: a propósito de Chartier. Relaciones. Estudios de historia y sociedad, 24, 17-499.

Serrano, P. (2009). Desinformación: cómo los medios ocultan el mundo. Barcelona: Península.

Serrano, Y. (2006). Conflicto armado e información: una reflexión sobre las reglas de conducta profesional periodística que dicta el Acuerdo por la discreción. Revista Diversitas, 2(1). Recuperado de http://goo.gl/DdaW2p.

Serrano, Y. (2010). El periodismo es noticia. Tendencias sobre comunicación en el siglo XXI. Barcelona: Icaria.

Torres, A. (2000). La sistematización desde la perspectiva interpretativa. En: Sistematización de experiencias, búsquedas recientes (pp. 23-37). Bogotá: Dimensión educativa.

Valcárcel, J.M. (enero-junio, 2007). Concepto de conflicto armado interno y seguridad jurídica. Revista Prolegómenos, X(19),. 107-121. Recuperado de http://goo.gl/TW84jI

Zúñiga, M. y Lehap, J. (Comp.) (2000). Sistematización de experiencias significativas en educación de adultos. En: Sistematización de experiencias, búsquedas recientes. Bogotá: Dimensión educativa. 


\section{Notas de prensa}

Flórez, M. (31 de octubre, 2014). Fallo acusa a medios de haber sido "complacientes" con las AUC. Periódico El Espectador. Recuperado de http:// goo.gl/mGgY0m.

Santos reitera su reconocimiento de que hay un conflicto armado en Colombia. (14 de mayo, 2011). W Radio. Recuperado de http://goo.gl/VQazyE

¿Qué significa el reconocimiento del conflicto armado por parte del gobierno? (4 de mayo, 2011). Revista Semana. Recuperado de http://goo.gl/ shJKBX

\section{Otros documentos}

Centro de Memoria, Paz y Reconciliación (s.f.). Multimedia Procesos de paz en Colombia. Recuperado de http://goo.gl/eJdGjm.

Comité Internacional de la Cruz Roja (1977). Protocolo II adicional a los Convenios de Ginebra de 1949 relativo a la protección de las víctimas de los conflictos armados sin carácter internacional. Recuperado de https://www.icrc.org/spa/resources/documents/misc/protocolo-ii.htm

De La Calle, H. (18 de octubre, 2012). Discurso de instalación de la mesa de diálogos de la paz. Oslo, Noruega. Recuperado de http://goo.gl/JS6hUZ.

Estrada, L. (Dirección). (2014). La dictadura perfecta [Película].

Márquez, I. (18 de octubre, 2012). Discurso de instalación de la mesa de diálogos de la paz. Oslo, Noruega. Recuperado de http://goo.gl/JS6hUZ.

Uribe, Á. (2002). Manifiesto democrático - 100 puntos Álvaro Uribe Vélez. Recuperado de http://goo.gl/bYmI3V.

\section{Fuentes primarias orales}

Alexander Becerra, Alter comunicador de Ingakuna estéreo.

Amado Grajales, Gerente de Piamonte estéreo. 
Bladimir Sánchez Espítia, Alter comunicador independiente, productor audiovisual.

Carlos Martínez Cuellar, Alter comunicador y director de Piamonte estéreo.

Diego Huaca, Alter comunicador de Piamonte estéreo.

Jhon Jairo Vásquez, Alter comunicador de Piamonte estéreo.

Jhonny Huaca, Alter comunicador de Ingakuna estéreo.

Líverman Rengifo, Alter comunicador y director de Ocaina estéreo, miembro de la Red de emisoras comunitarias del Putumayo, Cantoyaco.

René Ayala, Alter comunicador director de la Agencia Prensa Rural.

Richard Carlosama. Alter comunicador del Valle de Sibundoy.

Waira Nina Jacanamijoy Mutumbajoy, Alter comunicadora y directora de Ingakuna estéreo. 



\section{Sobre los autores}

Andrés Felipe Ortiz Gordillo (Investigador principal) Magister en Estudios Sociales, Especialista en Pedagogía de la Comunicación y Comunicador Social. Investigador social, educador y comunicador popular. Integrante del Proyecto CEIS (Colectivo de Estudios Investigación Social) y del Observatorio de Medios en Derechos Humanos, Medios al Derecho (MAD). Fue docente investigador de la Facultad de Comunicación de la Universidad Santo Tomás, integrante del grupo de investigación Comunicación, paz-conflicto. Correo electrónico: andresfortizg@yahoo.es.

LissetT M. ESPINEL TORRES

(Co-investigadora)

Comunicadora Social - Periodista de la Universidad Central, con estudios en Lingüística y Literatura Hispanoamericana del Instituto Caro y Cuervo y Maestría en Literatura Hispanoamericana de la Pontificia Universidad Javeriana. Fue docente investigadora de la Facultad de Comunicación de la Universidad Santo Tomás, integrante del grupo de investigación Comunicación, paz-conflicto. Con experiencia en tra- 
bajo con comunidades campesinas y organizaciones sociales de base. Correo electrónico: limiet@yahoo.com.

\section{Waira Nina Jacanamijoy Mutumbajoy}

(Líder de experiencia)

Indígena Inga. Alter comunicadora y artista, integrante de la emisora comunitaria indígena Ingakuna estéreo.

\section{LÍvERMAN RENGIFo GómeZ}

(Líder de experiencia)

Comunicador social comunitario, sensible a la situación política y social del país y la problemática socio económica de su población. Líder de procesos organizativos sociales. Alter comunicador integrante de la emisora comunitaria Ocaina estéreo y de la Red de emisoras comunitarias del Putumayo, Red Cantoyaco.

Carlos Martínez Cuellar

(Líder de experiencia)

Agricultor. Alter comunicador y ex director de la emisora comunitaria Piamonte estéreo. Líder comunitario del municipio de Piamonte, Cauca. 





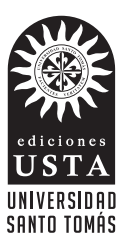

Esta obra se editó en Ediciones USTA,

Departamento Editorial de la Universidad Santo Tomás.

Se usó papel propalcote de 300 gramos para la carátula y papel bond beige de 75 gramos para páginas internas.

Tipografía Sabón Lt Std.

Impreso por Grupo Dao Digital, S.A.S.

2017. 
Las dinámicas del conflicto social y armado en Colombia son tan complejas y contradictorias, que han obligado a los alter comunicadores a establecer estrategias que les permitan defender los derechos comunicativos de sus comunidades, en medio del silencio y autocensura. En muchos territorios del país, la presión directa de los actores armados ha obligado a los alter comunicadores a dispersar la atención informativa hacia temas "de importancia menor", mientras intentan sortear creativamente ese contexto de violencia que les impone una implacable mordaza comunicativa.

Las múltiples experiencias alter comunicativas que se vienen gestando desde la ciudadanía en medio del conflicto, evidencian la emergencia de nuevos-otros espacios y lógicas comunicativas vinculadas a las comunidades, como resultado de la participación ciudadana en la definición e intervención colectiva de los asuntos públicos locales y regionales, y como contribución a los necesarios escenarios de paz que anda buscando el país.

Este libro explora, desde tres experiencias alter comunicativas situadas en áreas de influencia de actores armados de todas las pelambres, las problemáticas relaciones entre el conflicto, la comunicación y la construcción política de lo público. Teniendo en cuenta los contextos locales de estas experiencias, se busca interrogar el papel que cumplen los medios de comunicación en las dinámicas del conflicto social y armado, en lo que refiere a las representaciones que del conflicto y la paz se agencian desde la alter comunicación, para establecer sus características, incidencias y repercusiones en las dinámicas públicas locales, y para reconocer cómo estas experiencias han contribuido en el fortalecimiento de los procesos ciudadanos vinculados a la paz, la memoria y la democracia en Colombia.

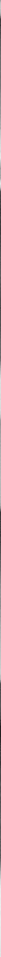

